\title{
Hyperbaric oxygen as a chemotherapy adjuvant in the treatment of osteosarcoma
}

\author{
YASUOMI KAWASOE ${ }^{1}$, MASAHIRO YOKOUCHI ${ }^{1}$, YOSHINORI UENO ${ }^{1}$, \\ HIROAKI IWAYA $^{2}$, HIROKI YOSHIDA ${ }^{3}$ and SETSURO KOMIYA ${ }^{1}$ \\ Departments of ${ }^{1}$ Orthopaedic Surgery, ${ }^{2}$ Emergency medicine, and ${ }^{3}$ Pathology, \\ Kagoshima Graduate School of Medical and Dental Sciences, Kagoshima 890-8520, Japan
}

Received June 22, 2009; Accepted July 30, 2009

DOI: $10.3892 /$ or_00000534

\begin{abstract}
Although hyperbaric oxygen has been shown to enhance the efficacy of radiotherapy and chemotherapy for the treatment of several malignant tumors, the impact of hyperbaric oxygen on osteosarcoma has not yet been demonstrated. In this study, we investigated the efficacy of hyperbaric oxygen alone and in combination with an anticancer drug as an adjuvant to chemotherapy. In vitro, highly metastatic murine osteosarcoma cell lines were exposed to hyperbaric oxygen and cell viability was examined. Hyperbaric oxygen alone significantly suppressed cell proliferation, and hyperbaric oxygen plus carboplatin exhibited significant synergism in suppression of cell proliferation. In vivo, $\mathrm{C} 3 \mathrm{H}$ mice were subcutaneously inoculated with osteosarcoma cells and divided into four groups: control, hyperbaric oxygen, carboplatin, and carboplatin plus hyperbaric oxygen. After 5 weeks, increase in both tumor volume and number of lung metastases was significantly suppressed in the hyperbaric oxygen group. Concomitant hyperbaric oxygen clearly enhanced the chemotherapeutic effects of carboplatin on both tumor growth and lung metastasis in osteosarcoma-bearing mice. Moreover, mortality in the carboplatin plus hyperbaric oxygen group was significantly lower than in the other three groups. These findings suggest that hyperbaric oxygen plus carboplatin combination therapy could be an appropriate therapeutic regimen for the treatment of patients with osteosarcoma.
\end{abstract}

\section{Introduction}

Osteosarcoma is the most common primary bone malignancy in adolescents and young adults $(1,2)$, and is characterized

Correspondence to: Dr Masahiro Yokouchi, Department of Orthopaedic Surgery, Kagoshima Graduate School of Medical and Dental Sciences, Kagoshima 890-8520, Japan

E-mail: masahiro@m3.kufm.kagoshima-u.ac.jp

Key words: osteosarcoma, hyperbaric oxygen, chemotherapy, lung metastasis by the proliferation of tumor cells producing osteoid. The efficacy of chemotherapy and its impact on the survival of osteosarcoma patients is well-documented, and the identification of effective neoadjuvant chemotherapy in combination with surgery for osteosarcoma patients has led to a significant improvement in outcome in recent decades. However, there are still a certain number of non-responders who do not benefit from these improvements. Despite advancements in multimodality treatment consisting of aggressive chemotherapy, metastasis develops in more than one-third of patients, $90 \%$ of whom rarely respond to salvage treatment (3). Fiveyear survival rates are still only about $40-50 \%$ (4), and drugresistant phenotypes remain a serious problem. It is therefore believed that new and alternative strategies for the treatment of osteosarcoma patients are necessary.

It is known that hypoxia is a common feature of various solid tumors (5). Insufficient vascularity creates a heterogeneous population of tumor cells lacking oxygen and nutrients in most regions of tumor except those in close proximity to blood vessels. The reduced cell division seen in areas of low oxygenation in tumors results in resistance to both radiotherapy $(6,7)$ and chemotherapy (8). Moreover, poorly vascularized areas of tumor may be perfused by sublethal levels of cytotoxic agents, leading to acquired resistance to chemotherapy. A recent study also demonstrated that hypoxia may be responsible for a variety of growth-modulating effects that could confer growth advantage upon cancer cells (9). Although the importance of hypoxia in osteosarcoma has not been clarified, Yang et al recently found that expression of hypoxia-inducible factor-1 (HIF-1), which has been suggested to be an endogenous marker of tumor hypoxia (10), significantly affected overall survival and disease-free survival in patients with osteosarcoma (11). This suggested that tumor hypoxia may also play a significant role in the treatment of osteosarcoma, and that modification of tumor hypoxia can therefore be considered an attractive therapeutic target in patients with osteosarcoma.

Hyperbaric oxygen (HBO) therapy has been applied clinically for the treatment of various diseases including air embolism, carbon monoxide poisoning, osteonecrosis, and non-healing wounds. HBO therapy involves the administration of $100 \%$ oxygen at high pressure. It dramatically increases the amount of oxygen dissolved in plasma, oxygenates hypoxic tissues, and promotes neovascularization, 
ultimately leading to increased blood flow (12). These characteristics of $\mathrm{HBO}$ are expected to increase the oxygen partial pressure within the tumor and render it more susceptible to radiotherapy. Indeed, HBO has been used extensively and successfully in radiotherapy to increase tumor radiation sensitivity and tumor oxygenation (5). In the same fashion, $\mathrm{HBO}$ is also expected to improve perfusion of chemotherapeutic agents in hypoxic tumor and the susceptibility of tumor cells to such drugs. It has therefore also been used in combination with chemotherapy for the treatment of malignancy (5). However, the impact of HBO on osteosarcoma as an adjuvant to chemotherapy has not yet been reported.

The effects of HBO alone in the treatment of malignancy remain controversial. The outcomes of experimental and clinical studies of the effects of HBO on cancers as standalone treatment have varied. Some studies have suggested that HBO may promote growth or recurrence of malignancy by promoting angiogenesis $(13,14)$ while other studies have demonstrated growth-inhibitory effects $(15,16)$. However, two independent groups recently extensively reviewed experimental and clinical data in the literature over the past 50 years, and concluded that intermittent $\mathrm{HBO}$ exposure had no stimulatory effects on primary or metastatic cancer growth $(5,17)$. It also seemed that $\mathrm{HBO}$ may have no tumor stimulatory effect on osteosarcoma. Therefore, the impact of HBO alone against osteosarcoma should be clarified.

The objective of the present study was to evaluate efficacy of HBO alone and in combination with an anti-cancer drug against osteosarcoma as an adjuvant to chemotherapy. Here, we demonstrated that $\mathrm{HBO}$ alone significantly reduced both tumor growth and lung metastasis of osteosarcoma. Moreover, concomitant HBO clearly enhanced the chemotherapeutic effect of carboplatin (CBCDA) against both cell growth and lung metastasis in osteosarcoma-bearing mice. In addition, HBO therapy in combination with CBCDA significantly increased survival. Our findings suggested that the relatively high levels of oxygen deliverable with $\mathrm{HBO}$ can be used in combination with chemotherapy to overcome lack of response to treatment in patients with osteosarcoma.

\section{Materials and methods}

Cells. The highly metastatic mouse osteosarcoma cell line LM8 (18) was obtained from RIKEN BioResource Center (Ibaraki, Japan). LM8 cells were cultured in Dulbecco's modified Eagle's medium (DMEM) (Sigma, USA) supplemented with $10 \%$ fetal bovine serum (FBS, HyClone, USA) and penicillin-streptomycin $(50 \mathrm{U} / \mathrm{ml})$ (Gibco, Invitrogen Corp., USA) at $37^{\circ} \mathrm{C}$ in a humidified $5 \% \mathrm{CO}_{2}$ atmosphere. Media were changed every 3 days.

Cell viability assay. Cell viability was determined by the MTT assay as described previously (19). In brief, LM8 cells were plated in 96-well culture plates at an initial density of $5 \times 10^{3}$ cells/well. After $24 \mathrm{~h}$, media were changed to fresh medium containing various concentrations of an anti-cancer reagent. Cells were then incubated for $48 \mathrm{~h}$. HBO therapy was administered at a pressure of $2.5 \mathrm{~atm}$ for $60 \mathrm{~min}$, and performed three times, just before the administration of drugs, at $24 \mathrm{~h}$ and at $48 \mathrm{~h}$. During the final $4 \mathrm{~h}$, cells were incubated with $10 \mu \mathrm{l}$ of MTT stock solution $(5 \mathrm{mg} / \mathrm{ml})$ (Sigma, Steinheim, Germany). Optical density was measured at $630 \mathrm{~nm}$.

Agarose gel electrophoresis of DNA fragmentation. 3T3 and LM8 were plated on $10-\mathrm{cm}$ dishes. HBO was performed and DNA was sampled after $48 \mathrm{~h}$. Cells were centrifuged at $5000 \mathrm{rpm}$ for $5 \mathrm{~min}$ and washed in PBS twice and then pelleted at $12000 \mathrm{rpm}$ for $10 \mathrm{~min}$. The pellet was resuspended in a lysis buffer (10 mM Tris- $\mathrm{HCl}$ buffer, $\mathrm{pH} 7.4,10 \mathrm{mM}$ EDTA, $\mathrm{pH} 8.0$, and $0.5 \%$ Triton $\mathrm{X}-100$ ) for $10 \mathrm{~min}$ at $4^{\circ} \mathrm{C}$ and centrifuged for $5 \mathrm{~min}$ at $4^{\circ} \mathrm{C}$. The cell extracts in $1.5 \mathrm{ml}$ Eppendorf tubes were mixed with $10 \mathrm{mg} / \mathrm{ml} \mathrm{RNase}$ for $1 \mathrm{~h}$ at $37^{\circ} \mathrm{C}$ and then $1 \mathrm{mg} / \mathrm{ml}$ proteinase $\mathrm{K}$ for $30 \mathrm{~min}$ at $50^{\circ} \mathrm{C}$, and $5 \mathrm{M} \mathrm{NaCl}, 1201$ at $-20^{\circ} \mathrm{C}$ overnight. The aliquots were centrifuged at $12000 \mathrm{rpm}$ for $15 \mathrm{~min}$, and supernatant was completely removed. The DNA was resuspended in TE buffer (10 mM Tris-HCl buffer, $\mathrm{pH} 7.4,1 \mathrm{mM}$ EDTA), and DNA samples were electrophoretically separated on $2.0 \%$ agarose gel containing ethidium bromide $(0.4 \mathrm{~g} / \mathrm{ml})$.

Animals. Five-week-old inbred $\mathrm{C} 3 \mathrm{H}$ female mice (CLEA Japan, Shizuoka, Japan) were housed in cages. Mice were maintained in a pathogen-free environment at $25^{\circ} \mathrm{C}$ under controlled lighting (12 h light/12 h darkness) and allowed free access to water and food pellets. All experiments with mice were approved by the Animal Care Committee of Kagoshima University, and the mice were given the most humane care possible.

$H B O$ protocol. Animals exposed to HBO were placed in cages in a specifically designed animal hyperbaric chamber (Nakamura Iron Works Co., Ltd.). HBO therapy was administered at a pressure of 2.5 atmospheres, $100 \% \mathrm{O}_{2}$ for $90 \mathrm{~min}$. A minimum of $15 \mathrm{~min}$ pressurization and $15-\mathrm{min}$ depressurization was allowed for animals to adjust to changes in pressure.

In vivo animal studies. In vivo experiments were performed on mouse osteosarcoma LM8 cells growing in $\mathrm{C} 3 \mathrm{H}$ mice. $\mathrm{C} 3 \mathrm{H}$ mice were subcutaneously inoculated with $5 \times 10^{6} \mathrm{LM} 8$ cells and divided into four groups: controls, HBO, CBDCA, and CBDCA plus HBO. The HBO group was exposed to $\mathrm{HBO}$ at 2.5 atmospheres absolute pressure for $60 \mathrm{~min}, 5$ times a week. The CBDCA group received weekly intraperitoneal CBDCA $(50 \mathrm{mg} / \mathrm{kg})(20,21)$. The CBDCA plus HBO group was treated with both $\mathrm{HBO}$ and CBDCA. Tumor size and number of surviving mice in each group were determined every week. After 5 weeks, mice were sacrificed and metastatic foci in the lung were counted. Serum samples were also taken. $\mathrm{CD} 19^{+} \mathrm{B}$ cells, $\mathrm{CD} 4^{+}$, and $\mathrm{CD}^{+} \mathrm{T}$ cells as well as $\mathrm{NK}$ cells were counted by FACS.

Histological analysis. Local tumors and lungs from treated and untreated animals were dissected, fixed with $10 \%$ buffered neutral formalin solution, and then embedded in paraffin in routine manner. Prepared sections were stained with hematoxylin-eosin (H\&E). 
A

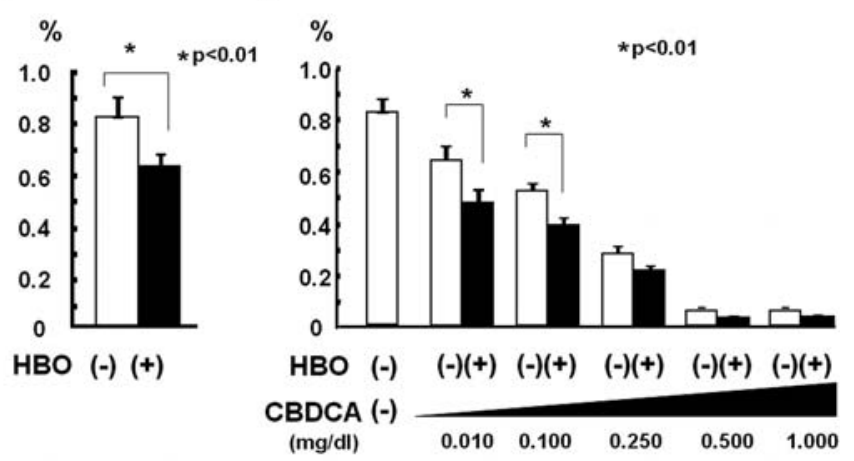

Figure 1. Effects of $\mathrm{HBO}$ on cell proliferation in vitro. (A) Equal numbers of LM8 cells were exposed to $\mathrm{HBO}$ (2.5 atmospheres, $100 \% \mathrm{O}_{2}, 60 \mathrm{~min}$ ) or normal-pressure air for $60 \mathrm{~min}$, and cell viability was examined by MTT assay. (B) LM8 cells were incubated for $48 \mathrm{~h}$ in the absence or presence of the indicated concentrations of CBDCA with or without $\mathrm{HBO}$ exposure. Optical density was measured at $630 \mathrm{~nm}$. The means of three experiments performed in quadruplicate are shown.

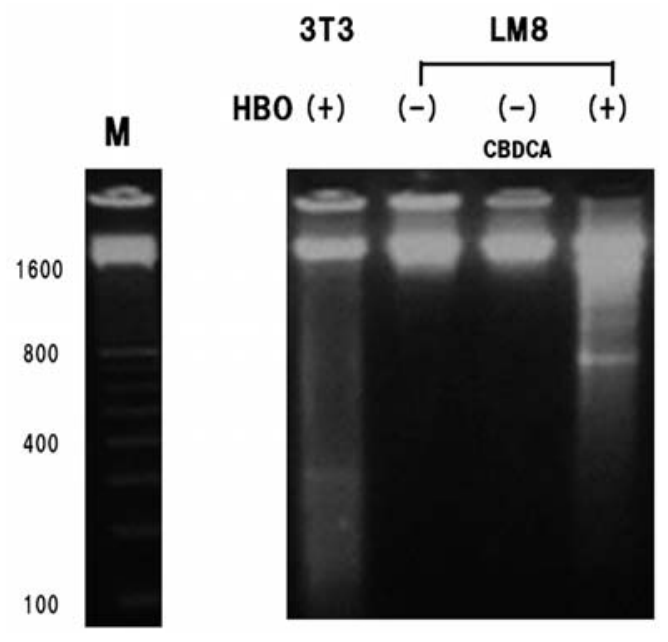

Figure 2. Electrophoretic analysis of intranucleosomal DNA fragmentation Equal numbers of LM8 cells were exposed to HBO (2.5 atmospheres, 100\% $\mathrm{O}_{2}, 60 \mathrm{~min}$ ) or normal-pressure air for $60 \mathrm{~min}$ and incubated for $48 \mathrm{~h}$. Agarose gel electrophoresis showed that $\mathrm{HBO}$ treatment increased intranucleosomal genomic DNA fragmentation for 48 h. Lane M, 100 bp DNA ladder.

Data analysis. Values are the mean \pm SD. Statistical analysis was performed using the unpaired t-test, and findings of $\mathrm{p}<0.05$ were considered significant.

\section{Results}

In vitro effects of $\mathrm{HBO}$ alone and in combination with CBDCA on LM8 cell proliferation. To evaluate the impact of $\mathrm{HBO}$ on osteosarcoma, we first examined the cytotoxic effect of HBO on LM8 cells by MTT assay. As shown in Fig. 1A, treatment with $\mathrm{HBO}$ alone significantly decreased the number of LM8 cells compared to untreated cells $(\mathrm{p}<0.01)$. Cell viability after 48 -h treatment with CBDCA was reduced in dose-dependent fashion, and concomitant $\mathrm{HBO}$ clearly enhanced the cytotoxic effect of CBDCA within the low dosage range, 0.01-0.1 mg/dl ( $<<0.01)$ (Fig. 1B).
A
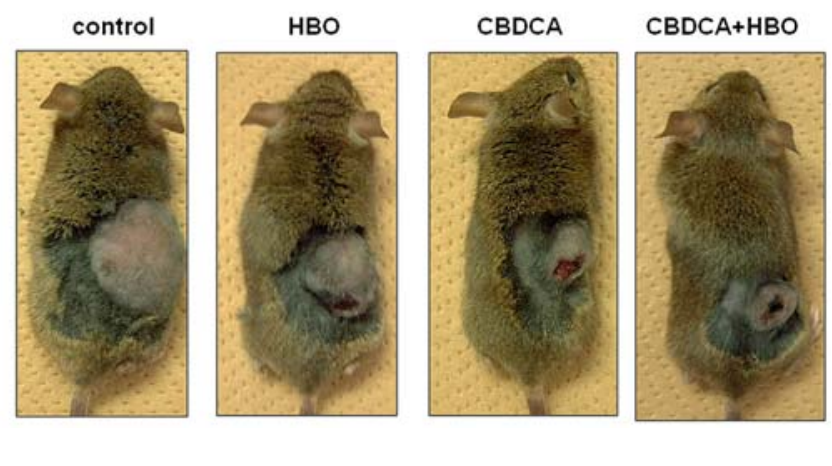

B

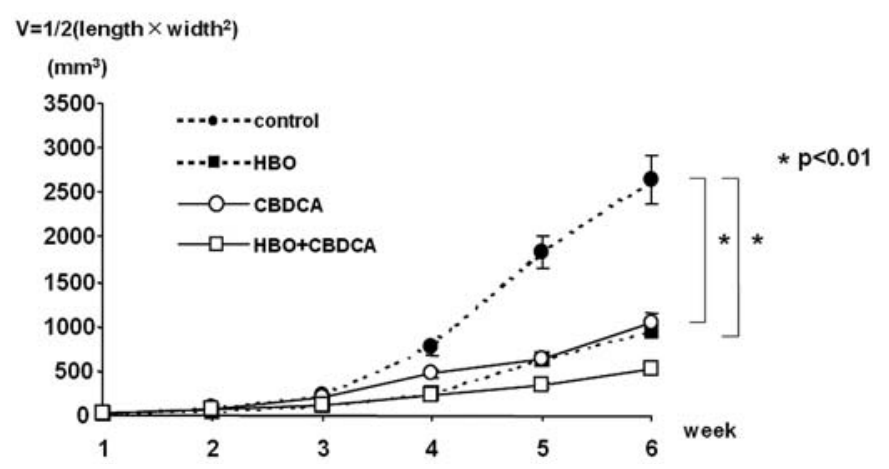

Figure 3. Effects of HBO on tumor growth in the mouse model. LM8 cells were inoculated s.c. in the back of $\mathrm{C} 3 \mathrm{H}$ mice on day 0 . The mice were divided into four groups as described in Materials and methods. (A) Representative picture showing gross appearance of the tumor. (B) Size of primary tumors evaluated weekly. Values are the mean $\pm \operatorname{SD}(n=6)$.

Induction by HBO of DNA fragmentation in LM8 cell line. To explore the mechanism underlying HBO-induced cytotoxicity, we examined whether $\mathrm{HBO}$ promotes apoptosis of osteosarcoma cells. DNA fragmentation analysis was performed in 3T3 and LM8 cells. Agarose gel electrophoresis showed that HBO increased intranucleosomal genomic DNA fragmentation in LM8 cells at $48 \mathrm{~h}$ after treatment (Fig. 2). These findings indicated that $\mathrm{HBO}$ has a direct effect on LM8 cells, probably involving induction of double-stranded DNA breaks. CBDCA addition group showed no ladder.

\section{Effects of $H B O$ alone and in combination with CBDCA in a mouse model}

HBO delays increase in tumor growth. In the control group, LM8 tumors increased rapidly in volume (Fig. 3). The increase in tumor volume was significantly suppressed in the HBO group in comparison with the control throughout the experiment $(\mathrm{p}<0.01)$. The increase in tumor volume was also delayed in the CBDCA group $(\mathrm{p}<0.01)$. Use of HBO together with CBDCA further decreased cell viability (Fig. 3). These findings indicated that a tumor suppressive effect of $\mathrm{HBO}$ alone and in combination with CBDCA was observed in vivo as well as in vitro.

HBO suppresses lung metastasis. LM8 was previously shown to form tumors with high potential for metastasis to the lung after transplantation into $\mathrm{C} 3 \mathrm{H}$ mice (18). Five weeks after inoculation of LM8 cells into the back of $\mathrm{C} 3 \mathrm{H}$ mice, numerous nodes were observed macroscopically on 
A

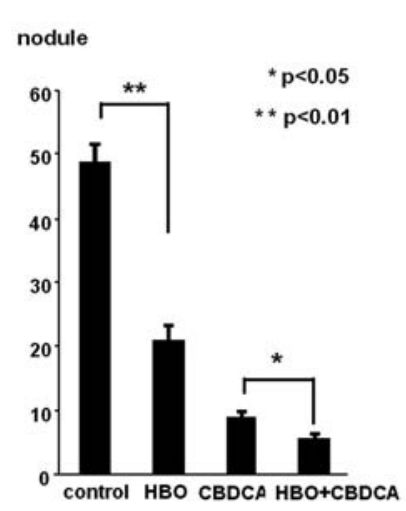

C

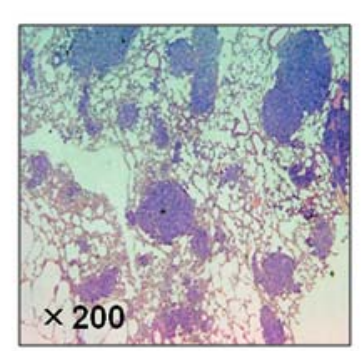

control

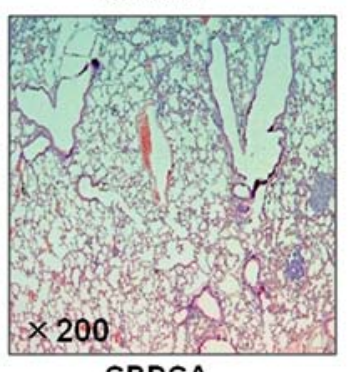

CBDCA
B

foci
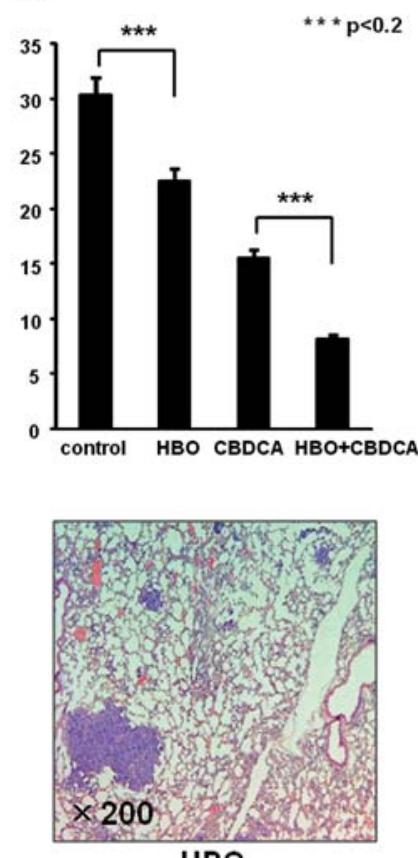

HBO

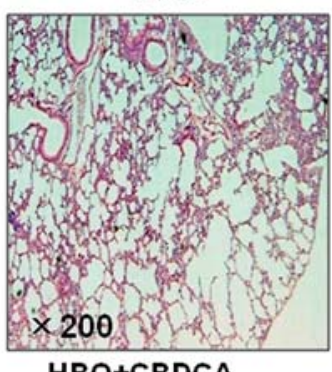

HBO+CBDCA

Figure 4. Effect of HBO on pulmonary metastasis in the mouse model. LM8 cells were inoculated s.c. in the back of $\mathrm{C} 3 \mathrm{H}$ mice on day 0 . The mice were divided into four groups as described in Materials and methods. After 5 weeks, mice were sacrificed and metastatic foci in the lungs were counted. (A) Quantitative analysis of metastatic nodules on the surfaces of lung. (B) Quantitative analysis of metastatic foci on large cut section of lung. (C) Representative microscopic pictures on a large cut section of lung (HE staining) showing the presence of metastatic nodules. Values are the mean $\pm \operatorname{SD}(n=6)$

the lung surfaces in the control group. Numbers of metastatic nodules on the surfaces of lung were significantly decreased in the HBO group $(p<0.01)$. Moreover, combination with HBO significantly decreased the numbers of metastatic nodules compared with CBDCA alone ( $<<0.05)$ (Fig. 4A). Although not to a significant extent, the number of metastatic foci on large cut sections of lung was also suppressed in the $\mathrm{HBO}$ group, and concomitant $\mathrm{HBO}$ enhanced the suppressive effect of CBDCA on pulmonary metastasis in osteosarcomabearing mice (Fig. 4B and C). These findings indicate that treatment with $\mathrm{HBO}$ can suppress not only the primary tumor but also pulmonary metastasis in a mouse model of osteosarcoma. Furthermore, HBO can be expected to improve the susceptibility of osteosarcoma as an adjuvant to CBDCA.

HBO affects mouse survival rate. Since our findings clearly demonstrated that HBO plus CBDCA significantly reduced both tumor growth and lung metastasis in osteosarcoma,

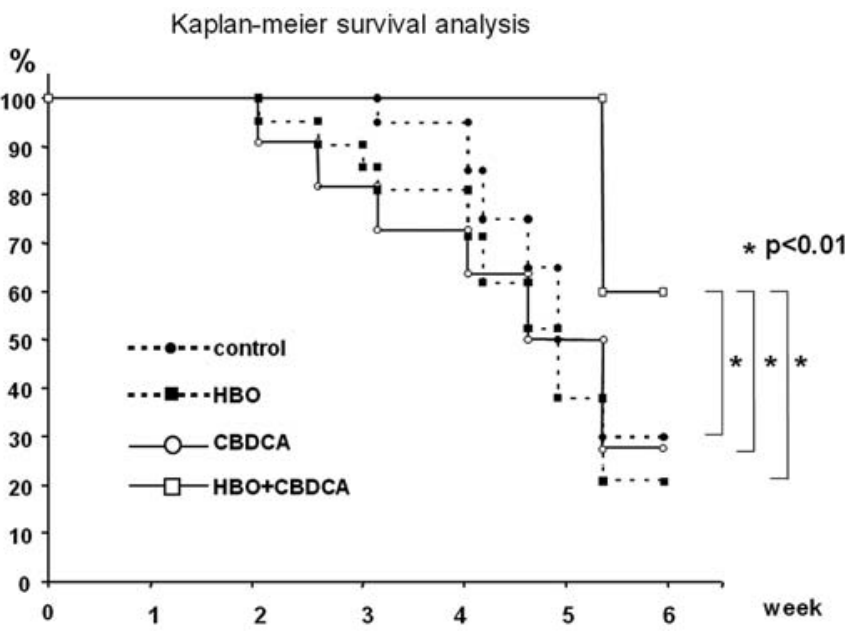

Figure 5. Effect of $\mathrm{HBO}$ on survival in the mouse model. LM8 cells were inoculated s.c. in the back of $\mathrm{C} 3 \mathrm{H}$ mice on day 0 . The mice were divided into four groups as described in Materials and methods. Survival data were analyzed by Kaplan-Meier methods, and survival periods were compared by the log-rank test. Values are the mean \pm SD $(n=8)$.

we expected that HBO therapy in combination with CBCDA would increase mouse survival rates. In the control group, tumor volume increased rapidly and pulmonary metastasis occurred. Mice became cachectic, and $50 \%$ of them died within 5 weeks (Fig. 5). In contrast, most mice lived for five weeks in the HBO plus CBDCA group, and Kaplan-Meier survival analysis demonstrated a higher survival rate in the HBO plus CBDCA group compared with the other three groups (Fig. 5). Although HBO alone also reduced both tumor growth and pulmonary metastasis, the survival rate in the HBO group was not increased compared with the control group.

\section{Discussion}

In the present study, it was shown both in vitro and in vivo that HBO, administered without any concomitant drug, exerts anti-tumor activity against osteosarcoma. This finding was unexpected. In the experiments using animals, treatment with HBO markedly suppressed local tumor growth compared to the control group and significantly suppressed remote metastasis of the tumor to the lungs. At present, HBO is used clinically in combination with radiotherapy and chemotherapy as a means of treating malignant tumors. However, no clear conclusion has been reached concerning the efficacy of uncombined HBO therapy against malignant tumors, since contradictory results concerning it have been reported. The first report on HBO-stimulated growth and spread of tumor was made in 1966 based on an analysis of clinical data from 25 patients with cancer of the neck (22), which demonstrated that exposure to HBO alone stimulated tumor metastasis. Subsequent animal and clinical studies revealed that exposure to HBO alone increased local blood flow and blood oxygen level through stimulation of vascularization, and thus stimulated the spread of tumor $(13,14,23)$. On the other hand, several studies found that exposure to HBO alone exerted anti-tumor activity $(15,16,24)$. The latter finding suggests that toxic effects of oxygen species (e.g., oxygen radicals) 
directly injure tumor cells, resulting in anti-tumor effects. However, no clear conclusion has yet been reached concerning the significance of these contradictory findings. In addition, no report has previously been published concerning the effects of uncombined HBO treatment on osteosarcoma.

In these circumstances, two independent study groups conducted and reported detailed reviews of studies published during the past 5 decades pertaining to combined treatment involving $\mathrm{HBO}$ for malignant tumors in clinical cases as well as in animals $(5,17)$. In one of these two reviews, Feldmeier et al (17) examined findings for all patients enrolled in clinical studies, and reported that although recurrence or progression of cancer was seen in 72 patients, $\mathrm{HBO}$ either suppressed tumor or had no impact on it in more than 3000 patients. The same investigators reported that $\mathrm{HBO}$ did not stimulate tumor progression in 15 of 17 animal studies reported after 1966, that mixed effects on tumor were found in the remaining 2 studies, and that HBO suppressed tumor progression in 6 additional studies. Similar conclusions were also reached in the review by Daruwalla et al (5). These two reviews thus suggest that exposure to $\mathrm{HBO}$ alone is unlikely to stimulate the growth of tumor cells in local or metastatic lesions and is more likely to exert anti-tumor activity. Daruwalla et al (5) reported that the effects of HBO varied depending on tumor type, stage, drug therapy regimen, and other factors, adding the noteworthy comment that high anti-tumor activity of HBO was observed in animal studies of sarcoma $(25,26)$. In fact, strong anti-tumor effects of HBO were shown in some other studies of the effects on BA1112 rhabdomyosarcoma, S-180 sarcoma, and other tumors $(27,28)$. There appear to have been no other reports on the contribution of HBO to tumor progression. In view of these findings, it seems likely that sensitivity to HBO differs between carcinomas (epithelial tumors) and sarcomas (nonepithelial tumors), and that sarcoma is more sensitive to $\mathrm{HBO}$. If this is the case, it may explain why uncombined treatment with $\mathrm{HBO}$ in our study exerted marked effects on osteosarcoma.

Although the mechanism of tumor cell suppression by uncombined HBO treatment remains unclear in detail, it has been reported that cell damage due to reactive oxygen species (ROS) or free radicals plays a role in mediating this effect of HBO (29). More specifically, tumor cells are destroyed if ROS level rises beyond the limit of a tumor's resistance to oxidative stress following treatment with $\mathrm{HBO}$. In fact, several recently published animal studies found that exposure to $\mathrm{HBO}$ alone induced tumor cell apoptosis (30-32). In the present study as well, DNA ladder formation was seen $48 \mathrm{~h}$ after treatment with $\mathrm{HBO}$, while none was observed in the group without HBO treatment. The present study thus demonstrated for the first time that exposure to HBO induces apoptosis of osteosarcoma cells. This finding suggests that induction of apoptosis is probably one of the mechanisms by which HBO suppresses osteosarcoma cell growth. In the past, resection was immediately performed when dealing with osteosarcoma without lung metastasis. Unfortunately, lung metastasis often occurred following such treatment, with a five-year survival rate of not more than $20 \%$ during some periods. This poor outcome indicated that micrometastasis to the lungs is already present in patients with osteosarcoma at the time of their first visit to the hospital in a majority of cases. In addition to control of local tumor, treatment beginning in the early stages of lung micrometastasis is essential. It is thus clear that the vital prognosis of osteosarcoma is determined by success or failure in the control of lung metastasis. In our evaluation of $\mathrm{C} 3 \mathrm{H}$ mice implanted with LM8 (a tumor cell line with high potential for lung metastasis), lung metastasis was markedly suppressed in the HBO-treated group compared to the control group. One possible mechanism of suppression of lung metastasis by HBO is suppression of local tumor growth, resulting in decrease in number of lung metastases. Furthermore, as indicated above, it is also possible that HBO suppresses lung metastasis through direct anti-tumor effects (stimulation of osteosarcoma cell apoptosis) and preservation of host immune function (33). To clearly determine the mechanisms of these effects of $\mathrm{HBO}$, it is essential to treat detectable lung metastases with $\mathrm{HBO}$ and to evaluate their responses to this therapy. An in vitro experiment using melanoma suggested another possible mechanism of suppression of lung metastasis, in which HBO inhibits cell adhesion and thus suppresses tumor potential for metastasis (34). In the present study, the mechanism of suppression of lung metastasis by sarcomas following treatment with HBO could not be fully clarified. However, the findings of this study do suggest that HBO therapy helps control lung metastasis, which is an important factor determining the vital prognosis of patients with osteosarcoma.

The current standard therapy for osteosarcoma is neoadjuvant chemotherapy composed of preoperative induction chemotherapy, surgical resection of tumor, and postoperative adjuvant chemotherapy. Among these, in determining the vital prognosis of patients, a central role is played by chemotherapy, which is aimed at controlling lung metastasis. In the present study, CBDCA (a platinum preparation and one of the key drugs in treatment of osteosarcoma) was used, and the effects of combined HBO + CBDCA therapy were evaluated. Treatment with CBDCA in combination with HBO resulted in significant increase in anti-tumor efficacy, leading to suppression of lung metastasis and improvement of survival rate. Hypotheses occasionally proposed to explain the mechanism for increased sensitivity of tumor to chemotherapy by combined use of HBO include the following: 1) Stimulation of vascularization in the area affected by tumor, increasing the amounts of drugs reaching tumor, 2) Reoxygenation of tumor, inducing it to enter the phase of division and thus become more sensitive to drugs. However, the reason for this effect on tumor sensitivity is still unclear. This may be related to the fact that the number of reports published on the efficacy of HBO in elevating the sensitivity of tumors to chemotherapy is less than that on the efficacy of HBO in increasing responsiveness to radiotherapy. Among experimental studies, reports are available on the effects of HBO used in combination with fluorouracil $(25,35)$ doxorubicin (26) paclitaxel (36) and other agents. However, only one clinical report on the combination of $\mathrm{HBO}$ and misonidazole (37) is available for this type of combined therapy. It can be expected that studies in this field will be further advanced; including analyses of changes in intracellular signal transduction related to hypoxia (38) as well 
as analyses using molecular biological approaches, to clarify the mechanism of HBO-induced potentiating of the effects of anti-cancer agents.

The objective of the present study was to evaluate the effects of HBO exposure on osteosarcoma (the most frequent type of primary malignant bone tumor) and to determine the possibility of clinical application of $\mathrm{HBO}$ as an auxiliary treatment of osteosarcoma. The primary question to be answered in this study was the effect of exposure to HBO alone on osteosarcoma cells. The findings of this study suggest that HBO therapy is unlikely to stimulate the growth or metastasis of osteosarcoma, at least under the conditions examined. Rather than stimulating osteosarcoma growth or metastasis, HBO markedly suppressed the growth of osteosarcoma and its metastasis to lungs in cell cultures and in animal experiments. HBO was additionally shown to reinforce the effects of CBDCA, resulting in significant suppression of osteosarcoma growth and lung metastasis compared to the group treated with CBDCA alone and significant reduction in the mortality rate of mice. These findings suggest that combined CBDCA + HBO therapy is a promising means of treating osteosarcoma and lung metastasis.

\section{Acknowledgements}

We thank Ms. Gao Hui for excellent technical assistance, and the members of our laboratories for many helpful discussions. This work was supported by the Grant of Japan Orthopaedics and Traumatology Foundation Inc. No. 0099.

\section{References}

1. Dorfman HD and Czerniak B: Bone cancers. Cancer 7: 203-210, 1995.

2. Whelan JS: Osteosarcoma. Eur J Cancer 33: 1611-1619, 1997.

3. Meyers PA and Gorlick R: Osteosarcoma. Pediatr Clin North Am 44: 973-989, 1997.

4. Bramwell VH: The role of chemotherapy in the management of non-metastatic operable extremity osteosarcoma. Semin Oncol 24: 561-571, 1997.

5. Daruwalla J and Christophi C: Hyperbaric oxygen therapy for malignancy: a review. World J Surg 30: 2112-2131, 1997.

6. Bush RS, Jenkin RD, Allt WE, et al: Definitive evidence for hypoxic cells influencing cure in cancer therapy. Br J Cancer 3: 302-306, 1978

7. Brown JM: Evidence for acutely hypoxic cells in mouse tumours, and a possible mechanism of reoxygenation. Br J Radiol 52: 650-656, 1979.

8. Teicher BA, Lazo JS and Sartorelli AC: Classification of antineoplastic agents by their selective toxicities toward oxygenated and hypoxic tumor cells. Cancer Res 41: 73-81, 1981

9. Graeber TG, Osmanian C, Jacks T, et al: Hypoxia-mediated selection of cells with diminished apoptotic potential in solid tumours. Nature 379: 88-91, 1996.

10. Yang QC, Zeng BF, Dong Y, et al: Overexpression of hypoxiainducible factor-1alpha in human osteosarcoma: correlation with clinicopathological parameters and survival outcome. Jpn J Clin Oncol 37: 127-134, 2007.

11. Vukovic V, Haugland HK, Nicklee T, et al: Hypoxia-inducible factor-1alpha is an intrinsic marker for hypoxia in cervical cancer xenografts. Cancer Res 61: 7394-7398, 2001.

12. Sheffield PJ: Measuring tissue oxygen tension: a review. Undersea Hyperb Med 25: 179-188, 1998.

13. Shewell $\mathbf{J}$ and Thompson SC: The effect of hyperbaric oxygen treatment on pulmonary metastasis in the $\mathrm{C} 3 \mathrm{H}$ mouse. Eur $\mathrm{J}$ Cancer 16: 253-259, 1980.

14. Valaitis j, Van Elk J and Staley CJ: Effect of hyperbaric oxygen and nitrogen mustard (NSC-762) on Ehrlich ascites tumor. Cancer Chemother Rep 52: 405-412, 1968.

15. DeCosse JJ and Rogers LS: Influence of high-pressure oxygen and chemotherapy on the AMel 4 hamster melanoma. Cancer Res 26: 287-292, 1966.
16. Dettmer CM, Kramer S, Gottlieb SF, Aponte GE and Driscoll DH: The effect of increased oxygen tensions upon animal tumor growth. Am J Roentgenol Radium Ther Nucl Med 102: 804-810, 1968.

17. Feldmeier J, Carl U, Hartmann K and Sminia P: Hyperbaric oxygen: does it promote growth or recurrence of malignancy? Undersea Hyperb Med 30: 1-18, 2003.

18. Asai T, Ueda T, Itoh K, et al: Establishment and characterization of a murine osteosarcoma cell line (LM8) with high metastatic potential to the lung. Int J Cancer 76: 418-422, 1998.

19. Hiraoka K, Zenmyo M, Komiya S, et al: Relationship of p21 (waf1/cip1) and differentiation in chondrosarcoma cells. Virchows Arch 440: 285-290, 2002.

20. Teicher BA, Herman TS, Holden SA, Epelbaum R, Liu SD and Frei E III: Lonidamine as a modulator of alkylating agent activity in vitro and in vivo. Cancer Res 51: 780-784, 1991.

21. Nakamura S, Kashimoto S, Kajikawa F and Nakata K: Combination effect of recombinant human interleukin 1 alpha with antitumor drugs on syngeneic tumors in mice. Cancer Res 51: 215-221, 1991 .

22. Johnson RJR and Lauchlan SC: Epidermoid carcinoma of the cervix treated by ${ }_{60} \mathrm{Co}$ therapy and hyperbaric oxygen. Proc Third Int Congress Hyperbaric Med, pp648-652, 1966.

23. Cade IS and McEwen JB: Megavoltage radiotherapy in hyperbaric oxygen. A controlled trial. Cancer 20: 817-821, 1967.

24. Henk JM: Late results of a trial of hyperbaric oxygen and radiotherapy in head and neck cancer: a rationale for hypoxic cell sensitizers? Int J Radiat Oncol Biol Phys 12: 1339-1341, 1986.

25. Takiguchi N, Saito N, Nunomura M, et al: Use of 5-FU plus hyperbaric oxygen for treating malignant tumors: evaluation of antitumor effect and measurement of 5-FU in individual organs. Cancer Chemother Pharmacol 47: 11-14, 2001.

26. Petre PM, Baciewicz FA Jr, Tigan S and Spears JR: Hyperbaric oxygen as a chemotherapy adjuvant in the treatment of metastatic lung tumors in a rat model. J Thorac Cardiovasc Surg 125: 85-95, 2003.

27. Martin DF, Porter EA, Rockwell S and Fischer JJ: Enhancement of tumor radiation response by the combination of a perfluorochemical emulsion and hyperbaric oxygen. Int J Radiat Oncol Biol Phys 13: 747-751, 1987.

28. Lian QL, Hang RC, Yan HF, et al: Effects of hyperbaric oxygen on S-180 sarcoma in mice. Undersea Hyperb Med 22: 153-160, 1995.

29. Conconi MT, Baiguera S, Guidolin D, et al: Effects of hyperbaric oxygen on proliferative and apoptotic activities and reactive oxygen species generation in mouse fibroblast $3 \mathrm{~T} 3 / \mathrm{J} 2$ cell line. J Investig Med 51: 227-232, 2003.

30. Raa A, Stansberg C, Steen VM, Bjerkvig R, Reed RK and Stuhr LE: Hyperoxia retards growth and induces apoptosis and loss of glands and blood vessels in DMBA-induced rat mammary tumors. BMC Cancer 7: 23, 2007.

31. Chen YC, Chen SY, Ho PS, et al: Apoptosis of T-leukemia and B-myeloma cancer cells induced by hyperbaric oxygen increased phosphorylation of p38 MAPK. Leuk Res 31: 805-815, 2007.

32. Stuhr LE, Raa A, Oyan AM, et al: Hyperoxia retards growth and induces apoptosis, changes in vascular density and gene expression in transplanted gliomas in nude rats. J Neurooncol 85: 191-202, 2007.

33. Lash GE, Postovit LM, Matthews NE, et al: Oxygen as a regulator of cellular phenotypes in pregnancy and cancer. Can J Physiol Pharmacol 80: 103-109, 2002.

34. Feldmeier JJ, Onoda JM, Bossung DE, Court WS and Alecu R: Effect of Hyperbaric oxygen on cancer cell metastatic potential and proliferation. Undersea Hyper Med 24: 125, 1997.

35. Stuhr LE, Iversen VV, Straume O, Maehle BO and Reed RK: Hyperbaric oxygen alone or combined with 5-FU attenuates growth of DMBA-induced rat mammary tumors. Cancer Lett 210: 35-40, 2004

36. Kalns J, Krock L and Piepmeier E Jr: The effect of hyperbaric oxygen on growth and chemosensitivity of metastatic prostate cancer. Anticancer Res 18: 363-367, 1998.

37. Sealy R, Cridland S, Barry L and Norris R: Irradiation with misonidazole and hyperbaric oxygen: final report on a randomized trial in advanced head and neck cancer. Int $\mathrm{J}$ Radiat Oncol Biol Phys 12: 1343-1346, 1986.

38. Postovit LM, Adams MA, Lash GE, Heaton JP and Graham CH: Oxygen-mediated regulation of tumor cell invasiveness. Involvement of a nitric oxide signaling pathway. J Biol Chem 277: 35730-35737, 2002. 